ISSN: $2594-4827$

\title{
A COMUNICAÇÃO ENTRE SURDOS E PROFISSIONAIS DA SAÚDE: UMA REVISÃO BIBLIOGRÁFICA
}

\section{Hélida Cristine Santos Mendes Barroso ${ }^{1}$}

Daniel Antunes Freitas ${ }^{2}$

Caio Bruno Wetterich ${ }^{3}$

Recebido em: fevereiro/2020

Publicado em: abril/2020

\section{RESUMO}

Este estudo objetivou conhecer a percepção do surdo e dos profissionais da saúde no atendimento à saúde pública do surdo e como se dá a comunicação entre eles. Trata-se de uma revisão bibliográfica baseada na literatura em língua portuguesa, no período de 2013 a 2018, através de consulta as bases de dados da Capes, LILACS, SciELO e Google acadêmico. Constatou-se nas pesquisas analisadas que a percepção dos surdos e dos profissionais da saúde remete-se a falta de comunicação em Libras como maior obstáculo para um atendimento à saúde integral e humanizado. Concluiu-se que a comunicação é essencial para um atendimento de qualidade e precisa ser efetivada com políticas públicas que visem inserir nos planos curriculares das escolas e universidades na área da saúde, na formação técnica e superior, a disciplina Libras. Dessa forma, o surdo será assistido na saúde com respeito à sua identidade e cultura surda, e reconhecido como sujeito de direitos na sua dignidade humana.

Palavras-chave: Surdos; Libras; Profissionais da saúde; atendimento à saúde; comunicação em Libras.

\footnotetext{
${ }^{1}$ Instituto Federal do Norte de Minas Gerais - Campus Montes Claros. E-mail: helidabarroso@yahoo.com ${ }^{2}$ Universidade Estadual de Montes Claros - Unimontes, E-mail: danielmestradounincor@yahoo.com ${ }^{3}$ Instituto Federal do Norte de Minas Gerais - Campus Januária. E-mail: caio.wetterich@ifnmg.edu.br
} 
ISSN: 2594-4827

\section{ABSTRACT \\ THE COMMUNICATION BETWEEN DEAF PEOPLE AND HEALTHCARE PROFESSIONALS: A BIBLIOGRAPHIC REVIEW}

This study aimed to analyze the perception of the deaf people and the health professionals in the public health care of the deaf and how communication takes place between them. This is a bibliographic literature review from 2013 to 2018 through queries as databases of Capes, LILACS, SciELO and Google Academic. It was possible to verify that the research analyzed about the perception of deaf people and health professionals has a lack of communication in LIBRAS as a major obstacle to a comprehensive and humanized health care. It has concluded that communication is essential for quality care and needs to be carried out with public policies that aim to insert in the curriculum plans of health schools and universities, in the technical and higher education, a LIBRAS discipline. In this way, the deaf people will be assisted in health with respect to their deaf identity and culture, and will be recognized as subject to the rights of their human dignity.

Keywords: Deaf; Libras; Health professionals; Health care; Communication in Libras.

\section{INTRODUÇÃO}

A luta contra a exclusão deveria estar presente em todos os segmentos da sociedade, contudo a realidade revela-se o contrário. Conforme preleciona Kaucharje "para a maioria das pessoas dos grupos minoritários cuja situação social é configurada pela pobreza, pela privação ou pela ineficácia no atendimento dos direitos sociais, a exclusão baseada na desigualdade social pode sobrepor-se, agravando e aprofundando outras exclusões fundamentadas na diferença" (KAUCHARJE, 2003, p.57). Constatase, sobremaneira, que no Brasil, as desigualdades sociais necessitam ser erradicadas.

Nesta perspectiva de desigualdade social, os direitos das pessoas com deficiência são reiteradamente desrespeitados provocando injustiças apoiadas na diferença, que se 
ISSN: 2594-4827

concretiza nas diversas formas e facetas da exclusão. O Ministério da Saúde e o Instituto Brasileiro de Geografia e Estatística (IBGE, 2013) mostram que 6,2\% da população brasileira possuem alguma deficiência, distribuída da seguinte forma: deficiência visual 3,6\%; deficiência intelectual $0,8 \%$; deficiência física $1,3 \%$; deficiência auditiva $1,1 \%$. Percebe-se diante desses índices o quantitativo de pessoas que se encontram de alguma maneira desassistida em seu desenvolvimento humano e nos seus direitos individuais e sociais, dentre eles o direito à saúde.

Conceber as pessoas com deficiências como sujeitos de direito é reconhecer seu direito perante a igualdade na participação, na configuração e na construção do espaço social que também é seu, segundo o entendimento de Kaucharje (2003). Nesse contexto de desassistência às pessoas com deficiência, encontra-se o surdo, que busca melhoria no atendimento à sua saúde. Perceber a realidade do surdo no atendimento à sua saúde, e promover meios para ressignificá-la torna-se essencial para reformar o pensamento sobre a inclusão e propor medidas de inclusão.

Diante disso, o objetivo desse trabalho é identificar, por meio de uma revisão bibliográfica, a percepção dos surdos e dos profissionais da saúde no que se refere ao atendimento à saúde do surdo, como se dá a comunicação entre eles e verificar que ações já foram tomadas e quais ainda necessitam ser implementadas na busca da solução ao problema apresentado.

\section{PERCURSO METODOLÓGICO}

O presente estudo trata-se de uma pesquisa de revisão bibliográfica que objetiva o levantamento dos principais trabalhos a respeito da percepção do surdo no atendimento à sua saúde, da percepção dos profissionais da saúde no atendimento à saúde do surdo e como se dá a comunicação entre eles. A revisão bibliográfica teve por finalidade a construção de uma contextualização sobre o problema e a análise das possibilidades presentes nas literaturas consultadas, de acordo com Alves-Mazzotti (2002).

Os trabalhos foram selecionados por meio de busca eletrônica nas bases de dados da Coordenação de Aperfeiçoamento de Pessoal de Nível Superior - Capes 
ISSN: 2594-4827

Periódicos, Google acadêmico, Literatura-Americana e do Caribe em Ciências da Saúde - LILACS e Scientific Electronic Library Online - SciELO. Na busca foram utilizados os descritores: ensino de libras AND saúde do surdo; surdo AND atendimento à saúde; comunicação com o surdo AND atendimento à saúde; enfermagem AND paciente surdo. Foram encontrados um total de 132 artigos, dos quais, 69 na Capes Periódicos, 52 no Google acadêmico, 10 na LILACS e 01 no SciELO. Diante desses dados, delimitamos o recorte temporal de busca entre 2013 e 2018, cinco anos, possibilitando a investigação de um panorama recente e atual. Além desse critério de inclusão, selecionamos artigos completos em língua portuguesa e que estivessem disponíveis online e abordassem o surdo e o atendimento à sua saúde. Foram excluídos os artigos que embora tratassem do surdo não se referiam ao atendimento de sua saúde e os artigos que não se enquadravam no espaço temporal delimitado.

Após esse levantamento, realizou-se a leitura criteriosa dos resumos a fim de mapear os trabalhos que abordassem o tema de interesse desse estudo. Diante disso, o corpus da pesquisa é constituído por um total de 14 artigos, a saber: três artigos da Capes Periódicos, sete do Google acadêmico, três artigos da LILACS e um do SciELO. Além dos artigos, também foram selecionados dois livros, dois decretos e um manual a fim de fundamentar a discussão dos resultados.

A análise qualitativa do material selecionado para construção da contextualização do problema se deu por meio da análise da percepção do surdo no atendimento a sua saúde, da percepção dos profissionais da saúde no atendimento à saúde do surdo e como se dá a comunicação entre eles. Nessa análise foram apontadas as possibilidades de um atendimento com mais segurança, autonomia e humanização presentes na literatura consultada, bem como, as lacunas existentes para pesquisas futuras.

\section{RESULTADOS E DISCUSSÃO}

\section{A percepção do surdo no atendimento a sua saúde pelos profissionais da saúde}


O surdo tem demonstrado ao longo de sua trajetória histórico-cultural ter vencido muitas dificuldades e obstáculos impostos pela sociedade por meio de preconceito, discriminação e desconhecimento de sua condição biológica e identitária. Nesse sentido, vamos abordar nessa primeira parte as concepções de surdez e de surdo e, em seguida, discutiremos a percepção do surdo no atendimento a sua saúde pelos profissionais da área.

\subsection{Quem sou eu? Concepções de surdez e de surdo}

Sabemos que muitas são as definições e conceituações acerca da surdez, e por sua vez do surdo, pessoa com surdez, deficiente auditivo. Desta forma, ressaltamos o conceito que fora construído por Campbell (2009, p. 97) pela sua relevância, mesmo fora do espaço temporal estipulado na pesquisa, "surdez como perda total ou parcial, congênita ou adquirida, da capacidade de compreender a fala por intermédio do ouvido". Outro conceito igualmente relevante e por isso também foi utilizado mesmo fora do lapso temporal da pesquisa é o construído por Skliar (2010, p. 11) como sendo, "a surdez constitui uma diferença a ser politicamente reconhecida; a surdez é uma identidade múltipla ou multifacetada". De acordo com a análise das pesquisas que serão apresentadas, classificaremos a surdez seguindo dois vieses: o biológico e o identitário, cada um se situando nos vieses citados, respectivamente.

Conforme o estudo de Nóbrega et al. (2012) com o advento da ciência moderna, contrariando a antiguidade clássica que pensava o nascido surdo como um ser que não raciocinava, estabeleceu-se o paradigma biomédico, na perspectiva científicomecanicista, de forma hegemônica, que enxerga a surdez e o surdo pela ótica da saúde, sob o ponto de vista orgânico-biológico ou fisiológico. Dessa forma, as pessoas com surdez passaram a ser definidas como deficientes auditivos. Com o avanço dos recursos tecnológicos e a intenção de transformar o surdo em ouvinte, surgiu o implante coclear, sendo considerado a terapia curativa da surdez. De maneira contra-hegemônica ao modelo médico ou biomédico da surdez e do surdo, houve o processo de construção cultural das identidades, que propõe o discurso da surdez calcado na diferença cultural e linguística, principalmente a partir do uso da Língua Brasileira de Sinais - Libras. 
Do mesmo modo, na pesquisa realizada por Magrini e Santos (2014), as autoras se utilizam do conceito do Ministério da Educação e Desporto - MEC para conceituar a deficiência auditiva como sendo a "perda total ou parcial, congênita ou adquirida, da capacidade de compreender a fala através do ouvido. Manifesta como surdez leve ou moderada, que é a perda de até 70 decibéis e surdez severa ou profunda que é a perda auditiva acima de 70 decibéis". Igualmente, Saraiva et al. (2017) utilizaram em seus estudos, a definição biológica da surdez, fundamentado no Decreto $n^{\circ}$ 5296/04, que também classifica a "surdez em leve/moderada e a surdez em severa/profunda", com os mesmos decibéis. Com essa compreensão, os autores se prendem em seus estudos somente na classificação biológica hegemônica da surdez e reforçam a moderada, como sendo aquela em o indivíduo se expressa oralmente e consegue perceber a voz humana; já na surdez severa, o indivíduo não percebe a voz humana e apresenta dificuldade em adquirir naturalmente a língua portuguesa.

No entanto, os autores Neves, Felipe e Nunes (2016) e Nóbrega et al. (2012) discutem em seus estudos a classificação biológica e identitária. Os autores definem a deficiência auditiva a partir da classificação biológica como a diminuição da capacidade de percepção dos sons e consideram a classificação identitária como aquela em que o surdo compreende e interage com o mundo por meio de suas experiências visuais, de sua cultura, a partir da Libras. Nessa perspectiva, os autores concluem que é na definição identitária da surdez que o surdo precisa ser reconhecido.

Nesse sentido, Nóbrega et al. (2012), acrescenta em sua pesquisa que a surdez na perspectiva do surdo, não se configura apenas no conceito biológico, mas como uma tessitura de ordem identitária e cultural. Nesse contexto de identificação e reconhecimento de quem se é ou de quem queira ser, faz-se necessário que o surdo e as pessoas interessadas na história de suas lutas e conquistas, que acreditam em seu direito à diferença enquanto pessoa humana e cidadão brasileiro, conheçam a realidade acerca do atendimento à saúde dos surdos e promovam ações efetivas na busca de solução aos problemas vivenciados. Para compreendermos melhor essa realidade, abordaremos a seguir as principais pesquisas de onde os surdos falam.

\subsection{De onde falo? Contexto histórico}


O lugar de onde se fala reflete as concepções que você tem de si e da carga histórico-social construída ao longo do tempo. A história mundial e brasileira do surdo é repleta de luta, sofrimento, conquistas e resistências que dinamizaram e promoveram tanto o desenvolvimento quanto a transformação de sua vida.

Por entender que o contexto histórico dos primórdios dessa luta já está bem escrito e difundido, decidimos fazer um recorte na história do surdo a partir do marco histórico do reconhecimento da democracia brasileira, a Constituição Cidadã, a Constituição da República Federativa do Brasil de 1988 (CF/88).

$\mathrm{Na} \mathrm{CF} / 88$ se reconhece os direitos individuais, coletivos e sociais de todas as pessoas, independentemente de cor, credo, raça, sexo, etnia, deficiência, trabalho, educação, lazer, cultura, seguridade e assistência social, na perspectiva do princípio da igualdade. Nesta norma legal foram reconhecidos os direitos e deveres coletivos e individuais em seus artigos $3^{\circ}$, IV e $5^{\circ}$; dos direitos sociais no artigo $7^{\circ}$, XXXI; da organização do estado no artigo 23, II e 24, XIV; da administração pública no artigo 37, VIII; da seguridade e assistência social artigo no 203, IV e V; da educação, cultura e desporto no artigo 208, II e IV; da família, da criança, do adolescente e do idoso no artigo 227, $\S 1^{\circ}$, II e $\S 2^{\circ}$. Alguns desses dispositivos serão, neste artigo, retomados para a análise da efetividade das políticas públicas já adotadas.

Contudo, no levantamento dos artigos e livros não se falou da percepção que o surdo tem acerca de seus direitos previstos na Constituição Federal. Porém, constatamos em um artigo de 2005, fora do recorte temporal proposto nesse trabalho, o estudo de Chaveiro e Barbosa (2005) que objetivou, dentre outros, discutir a assistência ao surdo na área de saúde. O tema foi abordado de maneira bem simplificada relatando que os surdos sabem que o direito à saúde é um bem fundamental, mas que eles acham que esse direito parece não estar sendo resguardado. Nota-se que são poucas as pesquisas que objetivaram buscar informações acerca da compreensão do surdo no que tange seus direitos no atendimento à sua saúde.

$\mathrm{Na}$ esfera educacional, após muita discussão, debates e embates em reconhecer qual seria a melhor metodologia a ser aplicada ao ensino do surdo, qual língua atenderia 
ISSN: 2594-4827

a construção de sua identidade e cultura, sua inserção social, é promulgada a Lei da Libras, Lei Federal nº 10.436 de 2002 que dispõe sobre a Língua Brasileira de Sinais Libras reconhecendo oficialmente a Língua dos Surdos: “Art. 1ํ É reconhecida como meio legal de comunicação e expressão a Língua Brasileira de Sinais - Libras e outros recursos de expressão a ela associados". Esse reconhecimento trouxe à comunidade surda a valoração de sua identidade e cultura e sua difusão ficaria a cargo do poder público como previsto no art. $2^{\circ}$ da lei.

Não obstante, no Decreto 5.626/05 dispõe, entre outros dispositivos, o $§ 1^{\circ}$ do artigo 26, a reserva de que 5\% (cinco por cento) dos servidores das unidades do serviço público fossem capacitados em Libras. Dispositivo que merece mais atenção de todos os envolvidos no reconhecimento da utilização da Libras na comunicação entre surdos e ouvintes.

\subsection{Para quem falo? Políticas públicas de inclusão}

Nesse primeiro item do artigo, a proposta seria desvelar por meio da revisão bibliográfica o que os autores pesquisados poderiam dizer acerca de cada subitem proposto. Dizer algo subentende-se que seja para alguém. As vozes apresentadas até aqui falaram para todos aqueles que conhecem e para aqueles que não conhecem a luta da comunidade surda em busca de seus direitos no reconhecimento político e social da sua identidade e cultura surda, enfim; essas vozes falaram para toda a sociedade brasileira. Abordaremos essa temática também sob dois vieses: educação e saúde.

A questão é: como falaram? A princípio gritaram com a promulgação da $\mathrm{CF} / 88$, todavia, com a pouca efetividade na aplicação da norma regente, a entonação da voz diminuiu, enfraqueceu e timidamente deu-se início as políticas públicas adotadas na educação e saúde.

De acordo com Campbell (2009), a partir da CF/88, na educação, foram criados cursos de Especialização para professores, cursos de estudos adicionais e com a parceria da Organização para a Educação, a Ciência e a Cultura das Nações Unidas (UNESCO) e o Centro Nacional de Educação Especial (CENESP) foram criados no Instituto Nacional de Educação de Surdos (INES), o Centro de Diagnóstico e Adaptação de Prótese 
ISSN: 2594-4827

Ortofônica na divisão de audiologia, tudo visando à capacitação e disseminação de conhecimento na área da surdez. O INES também ofertava aos alunos surdos desde a educação infantil ao ensino médio, assim como ensino profissionalizante, com o objetivo de inseri-los no mercado de trabalho.

Ainda na educação, com a Lei $n^{\circ}$ 10.456/02 que oficializou a Libras e o Decreto 5626/05 que a regulamentou, juntamente com o artigo 18 da Lei 10.098/00, houve algumas políticas que alavancaram o desenvolvimento do surdo. Previstos no artigo $3^{\circ}$, $\S 1^{\circ}$ do referido Decreto (BRASIL, 2005), a Libras deve ser inserida como disciplina curricular obrigatória nos cursos de formação de professores nos cursos de magistério, em nível médio e superior, nos cursos de fonoaudiologia, bem como em todos os cursos de licenciatura. Com essa legislação, a difusão da Libras se iniciou efetivamente devido à obrigatoriedade das Universidades e Faculdades em ofertá-la.

Por conseguinte, nota-se que além da regulamentação do Decreto 5626/05, outras políticas foram implementadas, tais como as ações que foram propostas pela Política Nacional de Educação Especial em 2007, como, por exemplo, o Programa de Educação Inclusiva que havia sido criado pelo MEC em 2003, mas não foi efetivado na prática (MEC, 2007). Dentre as ações, destacam-se a oferta de formação superior de professores e instrutores em Libras e a criação da função de tradutor e intérprete de Libras nas escolas, cuja profissão de Tradutor e Intérprete da Língua Brasileira de Sinais - Libras foi regulamentada através da Lei $n^{\circ} 12.319 / 2010$. Vale destacar também a implantação do atendimento educacional especializado - AEE nas salas de recurso, no período do contraturno. O AEE foi regulamentado pelo Decreto 6.571/08 com o acréscimo do artigo $9^{\circ}$ - A, passando a vigorar a partir de 2010 com o financiamento do Fundo de Manutenção e Desenvolvimento da Educação Básica e de Valorização dos Profissionais da Educação - FUNDEB, de tal modo que as escolas receberiam o cômputo em dobro para o atendimento dos alunos com deficiência nas salas de recurso.

Continuando nas ações propostas pela Política Nacional de Educação Especial de 1994, o MEC, em 2001, cria o Programa Nacional de Apoio à Educação de Surdos que em parceria com o INES e a Federação Nacional de Educação e Integração dos Surdos - FENEIS tinha por objetivo a oferta da educação bilíngue por meio da criação 
ISSN: 2594-4827

dos Centros de Capacitação de Profissionais da Educação e Atendimento às Pessoas com Surdez - CAS, com o oferecimento de condições adequadas para o desenvolvimento pleno das potencialidades dos estudantes surdos. Contudo, a oferta da educação bilíngue ainda não se efetivou de fato em todos os estados brasileiros. O Estado de Minas Gerais, por exemplo, ainda está em fase de implementação com um projeto de lei de no 919/2019 que se encontra em tramitação na Comissão de Educação Ciência e Tecnologia na Câmara Legislativa aguardando um parecer.

Diante dessa realidade, as autoras Ramos e Hayashi (2018) evidenciaram, na sua pesquisa que buscou identificar qual o lugar da educação dos surdos defendido nas dissertações e nas teses sobre o tema, que as inconsistências entre o sentido de educação bilíngue e de inclusão presentes no Decreto 5626/05 e na Política Nacional de Educação Especial na Perspectiva da Educação Inclusiva de 2008, fundamentaram-se em princípios político-ideológicos antagônicos, o que tem impossibilitado a interlocução entre suas orientações. Por sua vez, traz até os dias atuais consequências no planejamento e na implantação de uma educação bilíngue de qualidade para os surdos.

No que se refere à área da saúde, o que se viu foi à falta de adesão por parte do Ensino Superior, onde foram poucas as Universidades e Faculdades que ofertaram a disciplina em seus cursos, justamente pelo seu caráter optativo $\left(\S 3^{\circ}\right.$ do artigo $3^{\circ}$ do mesmo Decreto 5626/05), como fundamentado na pesquisa desenvolvida por Vieira, Caniato e Yonemutu (2017).

Nesse mesmo sentido, os artigos analisados de Magrini e Santos (2014), Neves, Felipe e Nunes ( 2016), Vieria, Caniato e Yonemotu (2017), que tratam da percepção do surdo na saúde, citam o Decreto 5626/05 que regulamenta, em seus capítulos VII e VIII, o atendimento do Sistema Único de Saúde - SUS e as empresas que detêm concessão ou permissão de serviços públicos de assistência à saúde do surdo por profissionais capacitados em Libras (pelos menos 5\% de seus profissionais) ou acompanhados por intérprete, como meio de assegurar a atenção integral à sua saúde, nos diversos níveis de complexidade e especialidades médicas. O Decreto veio regulamentar ações que deveriam ter sido implementadas desde a CF/88 que já disciplinava em seu artigo 23, inciso II, "cuidar da saúde e assistência pública, da proteção e garantia das pessoas 
ISSN: 2594-4827

portadoras de deficiência" que foram negligenciadas. No entanto, mesmo com Política Nacional da Saúde da Pessoa com Deficiência de 1994, as ações para garantir o direito dessas pessoas não foram alcançadas.

Em 2004, as políticas públicas adotadas pelo MEC por meio da portaria $\mathrm{n}^{\circ}$ 2.073/04 que institui a Política Nacional de Atenção a Saúde Auditiva, conforme apresentado nos estudos de Souza et al. (2017) e Nóbrega et al. (2012), cuja operacionalização iniciou a partir dos anos 2005 e 2006 com a realização de atendimento ambulatorial e cirurgia de implantes coclear nos surdos, também não foram suficientes para ofertar ao surdo um atendimento integral e humanizado.

\section{A percepção dos profisssionais da saúde no atendimento à saúde do surdo}

Para que se tenha uma boa percepção do outro é necessário que o conheça. Em relação à percepção dos profissionais da saúde no atendimento à saúde do surdo percebeu-se que os autores estudados criticam a formação dos profissionais da saúde no que tange ao ensino da Libras e os procedimentos adotados no atendimento ao surdo. A seguir vamos apresentar os trabalhos que abordam essa percepção.

\subsection{Formação técnica e tecnológica integral e integrada}

Os cursos de formação técnica e tecnológica integral e integrada proporcionam aos alunos conhecimentos teóricos e práticos necessários à formação profissional e que os habilitem exercer atividade profissional com vistas à atuação junto à realidade vivenciada, o que se concretiza através da oferta de um ensino em que as práticas reais comunguem com a teoria estudada em sala de aula. Desta forma, espera-se que os alunos desenvolvam o pensamento crítico e o conhecimento necessário para sua formação técnica, capacitando-o para ingressar no mundo do trabalho.

Não obstante, o que se vê na prática é um distanciamento daquilo que está previsto na legislação com a necessidade das pessoas que usufruem dos serviços prestados por um profissional. Nesse sentido, a interpretação que se faz da legislação pende para aquilo que seja mais funcional e menos dispendioso para as Instituições do que para a real necessidade de parte da população, como nesse estudo, os surdos. 
Vejamos, no $\S 2^{\circ}$ do artigo $3^{\circ}$ do Decreto $n^{\circ}$ 5.626/05: "A Libras constituir-se-á em disciplina curricular optativa nos demais cursos de educação superior e na educação profissional, a partir de um ano da publicação deste Decreto". O texto legal trata a disciplina como optativa, mas diante da realidade e necessidade dos surdos, os cursos técnicos, que se enquadram na educação profissional, poderiam ofertar a disciplina, mas se sentem acomodados por falta da obrigatoriedade no texto.

No levantamento realizado nas bases de dados citadas, não foi encontrado nenhum artigo que tratasse da temática, nos últimos 5 anos, para os cursos técnicos. Percebe-se a carência de escrita nessa área, supondo ser pela falta de problematização sobre o tema da inclusão de uma forma mais ampla. Diante disso, abordaremos a percepção que os profissionais da saúde, formados em cursos superiores, têm no atendimento ao surdo. Nos artigos de revisão bibliográfica analisados por Silva e Almeida (2017) e Sousa e Almeida (2017), as autoras concluíram que os profissionais da saúde sentiram muita dificuldade para lidarem com o surdo devido à falta de preparação e qualificação. As autoras sugerem que seja inserida nos cursos de graduação, a Libras, como disciplina obrigatória, e, para os profissionais já formados, cursos de capacitação em serviço. Nesse mesmo sentido, sugerimos que assim seja realizado nos cursos técnicos e tecnológicos da área da saúde para que realmente se tenha a formação integral e humanizada.

\subsection{Rede de atendimento integral e humanizada do SUS}

Os autores Nóbrega, Munguba e Pontes (2017) perceberam por meio da pesquisa que realizaram com um grupo focal de 15 surdos, que o atendimento dos surdos usuários da Libras é um desafio a ser superado. Tiveram como objetivo da pesquisa conhecer a assistência à saúde prestada às pessoas surdas, usuários da Língua Brasileira de Sinais - Libras, a partir da sua perspectiva, com vistas a refletir sobre a inclusão de ações na Rede de Cuidados à Pessoa com Deficiência. A pesquisa possibilitou aos autores conhecer as peculiaridades da assistência à saúde dos surdos com vistas a refletir sobre o acesso, cuidado humanizado e integral e o direito à saúde ante a proposta de implantação da Rede de Cuidados à Pessoa com Deficiência do SUS. 
ISSN: $2594-4827$

Nessa perspectiva, eles reconheceram as conquistas legais; contudo, relatam que os desafios a serem superados, devido às barreiras atitudinais, de comunicação e informação estabelecidas na relação interpessoal entre os pacientes surdos e os profissionais da saúde, limita o exercício de autonomia e a liberdade de escolha, infringindo a diretriz da Rede de Cuidados à Pessoa com Deficiência. Com isso, ressaltam a importância de políticas indutoras que atuem na realidade, que considerem as particularidades dos surdos e assegurem de modo efetivo seu direito à saúde reconhecido pela Constituição Cidadã.

Nesse mesmo espeque, os autores Saraiva et al. (2017) apontam na discussão de sua pesquisa os princípios doutrinários do SUS previstos na Lei 8.080/90 que se refere aos conceitos de igualdade e justiça, evidenciando o atendimento aos usuários de acordo com suas necessidades. Os autores ressaltam a persistência da falta de comunicação no atendimento ao surdo no serviço de saúde, mesmo tendo como princípio na Política Nacional de Atenção à Saúde Auditiva o reconhecimento das diferenças nas condições de vida e saúde das necessidades individuais de seus usuários.

\subsection{O atendimento ao paciente surdo, e agora?}

Independentemente de conhecer a Libras ou não, os profissionais da saúde tiveram, tem e terão pacientes surdos que necessitarão de atendimento à sua saúde. $\mathrm{O}$ que fazer? Ou melhor, o que fizeram, como fizeram e o que esperam que modifiquem para que esse atendimento melhore e se torne um atendimento integral e humanizado.

Após a análise de alguns trabalhos sobre a temática é possível afirmar que a comunicação foi e é um fator preponderante e essencial para um bom atendimento ao paciente surdo. Dentre esses trabalhos, destaca-se o estudo de Magrini e Santos (2014) com 40 funcionários de uma Unidade de Saúde do SUS, com o objetivo de investigar a comunicação dos funcionários com o paciente surdo e, consequente, cumprimento do decreto $n^{\circ} 5.626 / 05$. Os autores constataram os sentimentos de incapacidade, impotência e dificuldades na compreensão dos profissionais da saúde no que tange ao atendimento à saúde do surdo. E que esse atendimento é um desafio, tanto para os profissionais da 
ISSN: $2594-4827$

saúde quanto para o próprio surdo, necessitando conhecer novas estratégias de comunicação, dentre elas a Libras.

Nesse mesmo sentido, o estudo realizado em 2017 por Francisqueti et al. com 09 (nove) Unidades Básicas de Saúde e 198 (cento e noventa e oito) profissionais de enfermagem (enfermeiros, técnicos de enfermagem, auxiliares de enfermagem e agentes comunitários de saúde), teve como objetivo conhecer a percepção e sentimentos dos profissionais de saúde sobre as barreiras no processo de comunicação com os pacientes com deficiência auditiva. Constatou-se que 60,1\% dos profissionais da saúde descreveram que o atendimento proporcionado aos pacientes surdos é realizado com dificuldade devido ao processo de comunicação, sendo atribuída principalmente à falta de preparo. Diante dessas dificuldades, a maioria, $87,9 \%$ revela a importância de se capacitarem para o processo de comunicação, considerando as particularidades do surdo. Os autores de posse das informações dos sentimentos e percepção dos profissionais da saúde que relataram ter sentimentos de incapacidade, impotência, insegurança, constrangimentos, dentre outros; concluíram que a dificuldade se apresenta no processo de comunicação, apesar das leis e decretos que legislam sobre a preparação dos profissionais nesse sentido, o que ficou evidenciado pelo despreparo dos profissionais por não saberem se comunicar em Libras. Concluíram também que os profissionais sentem necessidade de se capacitarem para proporcionarem um melhor atendimento ao surdo, com equidade e qualidade. Percebe-se que estes sentimentos persistem, visto que a situação não se modificou mesmo com a publicação do Decreto $5.626 / 05$.

Corroborando com o artigo acima citado, os autores Saraiva et al. (2017) também observaram que o atendimento prestado pelos profissionais da saúde ao surdo é insuficiente no que se refere à comunicação com a utilização da Libras. Na pesquisa de revisão integrativa com objetivo de descrever a assistência aos surdos nos serviços de saúde do Brasil e as sugestões de melhoria desse atendimento, os autores constataram que a Política Nacional de Atenção à Saúde Auditiva e o princípio doutrinário constante na Lei 8.080/90 não têm garantido todos os direitos dos surdos. Principalmente, no que se refere à acessibilidade do surdo aos serviços de saúde, como o despreparo dos profissionais da saúde para a comunicação em Libras, o que torna o paciente surdo 
ISSN: $2594-4827$

dependente de acompanhamento de familiares, quebrando $\mathrm{o}$ princípio da confidencialidade entre pacientes e profissionais da saúde. Como sugestão de melhorias no atendimento, os autores apontaram para a necessidade de os profissionais da saúde entrarem em contato com a Libras na sua formação.

Conclui-se que, de acordo com as pesquisas analisadas, as críticas destinadas à formação dos profissionais da saúde e ao atendimento por eles realizado aos surdos se fundamentam basicamente na falta de comunicação em Libras, dificuldade essa que tem gerado consequências na autonomia do surdo, na confidencialidade entre profissional e paciente, no reconhecimento social das legislações existentes e por fim, na inclusão dos surdos na sociedade.

\section{A comunicação entre o surdo e os profissionais da saúde: como se dá?}

Podemos constatar até aqui, que a comunicação entre o surdo e os profissionais da saúde é um fator preponderante e essencial para que os desafios apontados na literatura sejam superados. Com essa expectativa analisamos, nesse último item, acerca da Libras, as barreiras e obstáculos existentes e das possíveis medidas de superação, apresentados pelos autores estudados.

\subsection{Libras, que Língua é essa?}

A Língua Brasileira de Sinais - Libras instituída pela Lei ${ }^{\circ}$ 10.436/02 em seu artigo $1^{\circ}$ dispõe sobre o reconhecimento: “Art. 1ํ É reconhecida como meio legal de comunicação e expressão a Língua Brasileira de Sinais - Libras e outros recursos de expressão a ela associados" e em seu parágrafo único a conceitua: "Libras a forma de comunicação e expressão, em que o sistema linguístico de natureza visual-motora, com estrutura gramatical própria, constituem um sistema linguístico de transmissão de ideias e fatos, oriundos de comunidades de pessoas surdas do Brasil".

Nesse contexto, os autores Silva, Basso e Fernandes (2014) objetivou revisar na literatura científica a importância da comunicação por meio da Libras, na assistência da saúde ao deficiente auditivo e em seu desenvolvimento. Os autores utilizaram-se da conceituação da Lei supracitada para definir a Libras e reforçar a condição da língua 
ISSN: 2594-4827

não ser uma língua de sinais universal. Cada país tem sua própria maneira de se comunicar e ela é constituída por uma estrutura gramatical própria, composta de combinações e gestos de mãos, associados com a expressão facial e corporal. Ressaltase que essa língua pode ser praticada por qualquer pessoa ou profissional da saúde e que o conhecimento dela é importante para se ter uma comunicação efetiva com os pacientes surdos.

No ano de 2018, numa abordagem histórico-cultural, as autoras Ramos e Hayashi (2018) em seu estudo que objetivou identificar qual o lugar da educação de surdos defendido nas dissertações e nas teses sobre o tema educação dos surdos, conceituou a língua de sinais como sendo uma língua de modalidade visual e espacial e acrescenta que é por meio dela que a criança surda organiza-se como ser da linguagem e desenvolve-se cognitiva, emocional e socialmente.

Com relação ao conhecimento da Libras enquanto língua de sinais do surdo, o trabalho de Ramos e Almeida (2017) buscou analisar a importância do estudo de Libras para uma melhor preparação profissional da saúde para atuar junto à comunidade surda e foi realizada com alunos de 5 tipos de áreas da saúde: enfermagem, farmácia, odontologia, fisioterapia e estética. O estudo revelou que 32 participantes da pesquisa sabem o que é Libras, 06 disseram não saber e 02 disseram saber um pouco sobre o assunto. Sobre a utilização da linguagem em Libras, 04 participantes disseram que utilizam da língua para se comunicarem com o surdo, 04 disseram que um pouco e 32 disseram que não. Com relação ao interesse em estudar Libras, 36 participantes declaram ter interesse e $100 \%$ dos profissionais da saúde alegaram que o ensino da Libras deveria fazer parte da grade curricular de todas as áreas de saúde. Os autores perceberam que poucas pessoas usam a Libras e que a comunicação em Libras facilitaria a compreensão do profissional da saúde e do surdo. Enfatizaram também que a incorporação da Libras nas grades dos cursos de graduação da área da saúde melhoraria a assistência aos surdos.

Conforme citação do $\S 2^{\circ}$ do artigo $3^{\circ}$ do Decreto $n^{\circ}$ 5.626/05 no item 2.1.2.1.2 dessa revisão, as autoras Pires e Almeida (2016) legitimam o descrito no texto legal e acrescem o desejo de que a disciplina Libras se faça como obrigatória em todos os 
cursos de educação superior relacionados à saúde, sob o argumento que o despreparo dos profissionais da saúde comprometa a eficácia dos atendimentos.

\subsection{Dificuldades e obstáculos existem?}

Em conformidade com os artigos dos autores analisados, nesse subitem foram tratadas as dificuldades e obstáculos na comunicação entre os profissionais da saúde e os surdos. Nesse diapasão, encontra-se a pesquisa realizada por Pires e Almeida (2016), com 26 estudantes surdos, que teve dentre os objetivos identificar os métodos de comunicação utilizados para atendimento aos surdos nos serviços de saúde. Segundo as autoras, de acordo com os relatos dos participantes, puderam identificar que existem dificuldades para um atendimento da saúde com qualidade, como a ausência e bloqueio de comunicação e o despreparo dos profissionais da saúde. Essas dificuldades prejudicam a relação entre os profissionais e os surdos, havendo o comprometimento no atendimento com a necessidade de intermediação pelo acompanhante, retirando-se assim do surdo o direito da individualidade no seu atendimento.

Sob o mesmo ponto de vista, os autores Souza et al. (2017) em seu estudo, tiveram como objetivo identificar os principais obstáculos e dificuldades enfrentadas por pessoas surdas quanto ao acesso à saúde, por meio de uma revisão integrativa que categorizou os obstáculos em 04 categorias, sendo eles: a barreira comunicacional, déficit de humanização na relação profissional-paciente, baixo conhecimento dos surdos sobre o processo de saúde-doença e o processo de inclusão dos deficientes auditivos na sociedade. Constatou-se que a dificuldade na comunicação entre os profissionais da saúde e surdos existe e está na barreira linguística devido à falta de treinamento dos profissionais, dificuldades financeiras para contratar intérpretes e ausência de adaptações para pacientes surdos. No déficit de humanização, foi apontada, pelos pesquisadores, a presença de acompanhante ou tradutor nas consultas, o que compromete o sigilo entre o profissional-surdo, tornando o atendimento menos humanizado. Quanto ao baixo conhecimento no processo saúde-doença, ressaltaram a marginalização do surdo nas campanhas e orientações preventivas pela falta de acesso às informações de educação em saúde. E por fim, no processo de inclusão, evidenciaram como entrave a maneira de expressão e socialização diferente dos ouvintes, o que 
ISSN: $2594-4827$

estigmatiza o surdo como aquele que não consegue atendimento adequado nos serviços de saúde.

Vale destacar também o estudo de Soares et al. (2018) que buscou responder o objetivo de descrever os saberes e as práticas de profissionais enfermeiros da atenção básica na assistência do usuário surdo, em uma pesquisa realizada com 20 enfermeiros atuantes nas Unidades Básicas de Saúde de Arapiraca em Alagoas. Nos resultados do estudo, as autoras identificaram duas unidades temáticas que apresentaram obstáculos a serem vencidos no atendimento à saúde do surdo sendo elas: o desconhecimento sobre a Libras e as práticas utilizadas pelos enfermeiros para viabilizar a interação com usuários surdos. Na primeira temática, foram relatados pelas autoras que os entrevistados por não saberem Libras, sentiram dificuldade na comunicação com o usuário surdo e foi apontado como um obstáculo ou barreira na relação entre eles e o paciente. Na segunda temática, foram apontadas algumas práticas: o acompanhante no atendimento, a utilização da escrita, a linguagem corporal e a utilização de outros sentidos (gestos, leitura labial). As autoras relataram que as estratégias apontadas pelos enfermeiros demonstram o desconhecimento da Libras, consideram a ausência de acompanhante como barreira no atendimento ao surdo e a necessidade de outros meios para a comunicação com os surdos.

Mediante o exposto, certifica-se que os obstáculos e barreiras no atendimento à saúde dos surdos existem e medidas para superação foram iniciadas; entretanto muitas delas persistem e a continuidade de ações que visem a total superação são urgentes e necessárias. Indubitavelmente, o próximo subitem tratará de ações que possam contribuir para essa superação.

\subsection{O que se pode fazer?}

O primeiro passo para resolução de um problema é conhecê-lo, depois se promovem ações ou estratégias de enfrentamento. Nota-se por todo texto já expresso que muitos problemas existentes no atendimento dos profissionais da saúde do surdo foram identificados e que muitas ações também foram tomadas, por outro lado, constata-se que foram insuficientes e ineficazes. 
ISSN: 2594-4827

Nessa perspectiva, os autores estudados trazem em suas pesquisas sugestões de ações que possam ser um caminho para que os obstáculos e barreiras existentes e persistentes findem-se. Pires e Almeida (2016) sinalizaram no sentido de ter presente o intérprete no atendimento ao surdo como um meio que facilitaria a comunicação, embora não resolvesse integralmente o problema. Por isso, propuseram a implantação da Libras como disciplina obrigatória nos cursos de graduação da área da saúde.

Para Soares et al. (2018), as ações pertinentes para um atendimento humanizado à saúde do surdo estariam vinculadas à importância do acolhimento do surdo por profissionais treinados em Libras com a compreensão do surdo como um sujeito multicultural e bilíngue. Sugeriram também que as campanhas públicas de autocuidados e prevenção à saúde sejam executadas também de maneira visual, por meio de legendas ou desenhos ilustrativos. Sugestões que também são apresentadas nos estudos de Neves et al. (2016). No mesmo entendimento, Soares et al. sugerem além da inserção da Libras como disciplina nos cursos de graduação, também a capacitação em serviço.

Enfim, as semelhanças das propostas em todos os artigos analisados, resumemse na valorização da identidade e cultura surda por meio do reconhecimento social da Língua com estratégias de disseminação desta nos planos curriculares de todos os cursos das universidades voltados para a área da saúde.

\section{CONSIDERAÇÕES FINAIS}

Este estudo bibliográfico permitiu evidenciar a percepção dos surdos e dos profissionais da saúde no atendimento à saúde, e constatou-se que ambos veem a comunicação em Libras como o maior obstáculo para um atendimento integral e humanizado.

Em decorrência da falta de comunicação vários problemas foram percebidos por eles, para o surdo. Por exemplo: o atendimento hospitalar e saúde primária de maneira inadequada e insatisfatória, a escassez de informações em Libras sobre saúde, exames, procedimentos e tratamentos, despreparo dos profissionais em Libras. Com relação aos profissionais da saúde foram percebidos: a falta de formação dos profissionais da saúde em Libras, o comprometimento da autonomia e da confiabilidade do surdo no que diz 
ISSN: 2594-4827

respeito ao sigilo entre profissional e paciente, o reconhecimento social das legislações existentes.

Por fim, conclui-se que as percepções dos surdos e dos profissionais da saúde mostraram que o atendimento à saúde do surdo precisa ser repensado numa perspectiva inclusiva, na valorização da identidade e cultura surda com o reconhecimento e utilização da Libras na comunicação. E isso só será possível se for inserida a Libras nos planos curriculares de todos os cursos, sejam eles superiores ou profissionais, bem como a oferta da Libras em cursos de capacitação em serviço para atender os profissionais que já se formaram. Tudo perpassa pela educação e pela formação no seu sentido lato.

Em 2018, a comunidade surda recebeu o apoio dos professores de Libras, no $2^{\circ}$ Encontro Nacional de Professores de Libras no Ensino Superior, que tiveram como um dos objetivos redigir um termo de compromisso apresentado ao candidato a Presidente da República Jair Bolsonaro constando as reivindicações da comunidade surda no que tange a educação bilíngue constante no Decreto 5626/2005. Em 02 de janeiro de 2019, foi instituído o Decreto 9.665 que dispõe sobre a criação da Diretoria de Políticas de Educação Bilíngue de Surdos no MEC, constante em seu artigo 35 ações que visam à implementação de políticas de educação bilíngue, que considerem a Língua Brasileira de Sinais (Libras), como primeira língua, e Língua Portuguesa Escrita, como segunda do surdo. Encontra-se em tramitação no Senado Federal o projeto de lei $n^{\circ}$ 6284, de 2019, conforme ementa, altera a Lei 9.394/1996 que estabelece as diretrizes e bases da educação nacional, para estabelecer condições de oferta de ensino de Libras, em todas as etapas e modalidades da educação básica. Diante do exposto, vislumbra-se um panorama futuro de possibilidade de melhoras no atendimento à saúde do surdo devido a criação dessa diretoria e da aprovação do referido projeto de lei.

\section{REFERÊNCIAS}

ALVES-MAZZOTTI, A. J. A "revisão bibliográfica" em teses e dissertações: meus tipos inesquecíveis - o retorno. In: BIANCHETTI, L.; MACHADO, A. M. N. (Org.). 
A bússola do escrever: desafios e estratégias na orientação de teses e dissertações. São Paulo: Cortez, 2002. p. 25-44.

ATIVIDADE LEGISLATIVA. Senado Federal. Projeto de Lei 6284/2019. Altera a Lei n 9.394 , de 20 de dezembro de 1996, que estabelece as diretrizes e bases da educação nacional, para estabelecer condições de oferta de ensino da Língua Brasileira de Sinais LIBRAS, em todas as etapas e modalidades da educação básica. Disponível em: < https://www25.senado.leg.br/web/atividade/materias/-/materia/140061>. Acesso em: 04 fev. 2020.

BRASIL. Decreto $n^{\circ} 5.626$, de 22 de dezembro de 2005. Regulamenta a Lei $n^{\circ} 10.436$, de 24 de abril de 2002 - Dispõe sobre a Língua Brasileira de Sinais - Libras.

BRASIL. Decreto n. 9.665, 02 de janeiro de 2019. Aprova a Estrutura Regimental e o Quadro Demonstrativo dos Cargos em Comissão e das Funções de Confiança do Ministério da Educação. Diário Oficial da União, DF, 02/01/2019. Disponível em: <http://www2.camara.leg.br/legin/fed/decret/2019/decreto-9665-2-janeiro-2019787572-publicacaooriginal-157191-pe.html>. Acesso em: 04 fev. 2020.

CAMPEBELL, Selma Inês. Múltiplas faces da Inclusão. Rio de Janeiro: Wak Ed., 2009.

FRANCISQUETI, Verônica et al. Sentimentos da equipe de enfermagem ao atender um paciente com deficiência auditiva: desafios do cuidado. Revista Educação, Artes e Inclusão. Volume13, No 3, Set./Dez. 2017, ISSN 1984-3178.

IBGE. Instituto Brasileiro de Geografia e Estatística. Censo 2010. In: Montes Claros. Disponível em: <http://agenciabrasil.ebc.com.br/geral/noticia/2015-08/ibge-62-dapopulacao-tem-algum-tipo-de-deficiencia>. Acesso em $10 \mathrm{dez} .2018$.

KAUCHARKJE, Samira. "Comunidade surda": as demandas identitárias no campo dos direitos, da inclusão e da participação social. In SILVA, Ivani Rodrigues; KAUCHARKJE, Samira; GESUELI, Zilda Maria. (Org.). Cidadania, surdez $e$ linguagem: desafios e realidades. - São Paulo: Plexus Editora, 2003, p.57 a 76.

MAGRINI, Amanda Monteiro; SANTOS, Tereza Maria Momensohn. Comunicação entre funcionários de uma unidade de saúde e pacientes surdos: um problema? Revista Distúrbios da Comunicação, 26(3):550-558, setembro, 2014.

MEC. SECAD. Política Nacional de Educação Especial em 2007. Disponível em: <http://portal.mec.gov.br/seesp/arquivos/pdf/politica.pdf>. Acesso em 07 jan. 2019.

MINAS GERAIS. Assembleia Legislativa. Projeto de Lei 919/2019. Cria escolas bilíngues em Libras e Português na rede pública estadual de educação. Disponível em: < https://www.almg.gov.br/atividade_parlamentar/tramitacao_projetos/interna.html?a=20 19\&n=919\&t=PL>. Acesso em: 03 fev. 2020. 
NEVES, Dayane Bevilaqua; FELIPE, Ilana Mirian Almeida; NUNES, Serlyjane Penha Hermano. Atendimento aos surdos nos serviços de saúde: acessibilidade e obstáculos. Revista Infarma Ciências farmacêuticas. v.28 ed 3. 2016. pp157-165.

NÓBREGA, Juliana Donato et al. Identidade surda e intervenções em saúde na perspectiva de uma comunidade usuária de língua de sinais. Revista Ciência \& Saúde Coletiva, 17(3): 671-679, 2012.

PIRES, Hindhiara Freire; ALMEIDA, Maria Antonieta Pereira Tigre. A percepção do surdo sobre o atendimento nos serviços de saúde. Revista Enfermagem Contemporânea. 2016 Jan./Jun. 5(1):68-77.

RAMOS, Denise Marina; HAYASHI, Maria Cristina Piumbato Innocentini. O lugar da Educação dos Surdos nas dissertações e teses. Revista Brasileira de Educação Especial. Marília, v.24, n.2, p.247-260. Abr.-Jun., 2018.

RAMOS, Tâmara Silva; ALMEIDA, Maria Antonieta Pereira Tigre. A Importância do ensino de Libras: Relevância para Profissionais de Saúde. Revista Multidisciplinar e de Psicologia. Vol. 10, N. 33. Janeiroq2017 - ISSN 1981-1179.

SARAIVA, Francisco Joilsom Carvalho et al. (2017). O silêncio das mãos na assistência aos surdos nos serviços de saúde brasileiros. Revisita Eletrônica Multidisciplinar. n. 17, vol. 2, Ano 2017. ISSN 2176-9249.

SILVA, Paulo Sergio da; BASSO, Neusa Aparecida de Sousa; FERNANDES, Sônia Regina Chaves Martines. A enfermagem e a utilização da Língua Brasileira de Sinais no atendimento ao deficiente auditivo. Revista Uningá Review, Vol. 17, n. 1, pp. 05-12 (Jan - Mar 2014). ISSN on line 2178-2571.

SILVA, Raira Piágio Silva; ALMEIDA, Maria Antonieta Pereira Tigre. Relação Comunicativa entre o Profissional de Saúde e Surdos: Uma Revisão Bibliográfica. Revista Multidisciplinar e de Psicologia. V.11, N.37, 2017 - ISSN 1981-1179.

SKLIAR, Carlos. Um olhar sobre o nosso olhar acerca da surdez e das diferenças. In A surdez: um olhar sobre as diferenças. Porto Alegre: Mediação, 2010, (4 ${ }^{\mathrm{a}}$ ed. atual. artog.).

SOARES, Imaculada Pereira et al. Como eu falo com você? A comunicação do enfermeiro com o usuário surdo. Revista Baiana de Enfermagem (2018);32:e25978.

SOUSA, Eliane de Sousa; ALMEIDA, Antonieta Pereira Tigre Almeida. Atendimento ao surdo na atenção básica: perspectiva da equipe multidisciplinar. Revista Multidisciplinar e de Psicologia. V.10, N.33. Janeiro/2017 - ISSN 1981-1179.

SOUZA, Maria Fernanda Neves Silveira de et al. Principais dificuldades e obstáculos enfrentados pela comunidade surda no acesso à saúde: uma revisão integrativa de literatura. Revista CEFAC. 2017 Maio-Jun; 19(3):395-405. 
ISSN: 2594-4827

VIEIRA, Camila Mugnai; CANIATO, Daniela Gimenez; YONEMOTU, Bianca Pereira Rodrigues. Comunicação e acessibilidade: percepções de pessoas com deficiência auditiva sobre seu atendimento nos serviços de saúde. Revista Eletrônica de Comunicação, Informações e Inovações em Saúde. 2017 abr.-jun.; 11(2) e - ISSN 1981-6278. 